\title{
Pineapple consumption reduced cardiac oxidative stress and inflammation in high cholesterol diet-fed rats
}

\author{
Porrnthanate Seenak ${ }^{1,2}$, Sarawut Kumphune ${ }^{1,3}$, Wachirawadee Malakul ${ }^{4}$, Ratanon Chotima ${ }^{5}$ and \\ Nitirut Nernpermpisooth ${ }^{1,2^{*}}$ (1)
}

\begin{abstract}
Background: Hypercholesterolemia is a major risk factor for cardiovascular disease. It has been reported that pineapple contains healthy nutrients and phytochemicals associated with antioxidant and anti-inflammatory capacities. No investigation exists concerning the effect of pineapple consumption modulating hypercholesterolemia-induced cardiac damage in high-cholesterol diet (HCD)-fed rats. This study evaluated the effect of pineapple consumption on lipid-lowering, cardiac oxidative stress and inflammation in HCD-fed rats.

Methods: Male Sprague-Dawley rats were fed with HCD, in the presence and absence of Pineapple (Ananas comosus L.) CV. Pattavia powder for 8 weeks. Then, serum lipid profiles, liver and renal function tests, cardiac oxidative stress and pro-inflammatory cytokines were determined.

Results: Daily pineapple consumption reduced weight gain, serum lipid profiles, atherogenic coefficient (AC), cardiac risk ratio (CRR), and liver enzyme activity, without causing renal dysfunction. Pineapple consumption also restores cardiac protein carbonyl (CPC) content, reduces cardiac malondialdehyde (MDA), cardiac pro-inflammation cytokine IL-6 and IL-1 $\beta$ levels.

Conclusion: Pineapple possesses antioxidant and lipid-lowering properties and daily consumption alleviates hypercholesterolemia-induced cardiac lipid peroxidation and pro-inflammation elevation in an in vivo model. This study demonstrates that pineapple is a potential candidate for cardioprotection against hypercholesterolemia.
\end{abstract}

Keywords: Pineapple, Oxidative stress, Cardiac inflammation, Hypercholesterolemia

\section{Introduction}

Hypercholesterolemia is a major metabolic disorder, which is considered a major risk for cardiovascular morbidity and mortality. Outcomes of unhealthy high-cholesterol diet (HCD) consumption or familial hypercholesterolemia (FH) abnormally increase lipids in the circulation and accumulation in particular tissues [1]. Lipids are the main source of energy required

\footnotetext{
*Correspondence: nitirutn@nu.ac.th

${ }^{1}$ Integrative Biomedical Research Unit (IBRU), Faculty of Allied Health Sciences, Naresuan University, Phitsanulok 65000, Thailand

Full list of author information is available at the end of the article
}

for cardiac pumping function [2-4]. Prolonged HCDinduced hypercholesterolemia has been implicated in lipid accumulation in the heart [4-7]. Excessive lipid overload in the myocardium is prone to be harmful by disrupting ion channels and membrane integrity [2-8]. Lipid oversupply into the heart and fat accumulation in cardiomyocytes, produces lipotoxicity from fatty acid oxidation and uncoupling mitochondrial ROS production, which leads to myocyte loss through apoptosis $[2-5$, $9,10]$. These highly reactive species mediate low-grade inflammation by inducing oxidative damage locally to cardiac lipid and protein molecules [10, 11]. Therefore, original author(s) and the source, provide a link to the Creative Commons licence, and indicate if changes were made. The images or other third party material in this article are included in the article's Creative Commons licence, unless indicated otherwise in a credit line to the material. If material is not included in the article's Creative Commons licence and your intended use is not permitted by statutory regulation or exceeds the permitted use, you will need to obtain permission directly from the copyright holder. To view a copy of this licence, visit http://creativecommons.org/licenses/by/4.0/. The Creative Commons Public Domain Dedication waiver (http://creativeco mmons.org/publicdomain/zero/1.0/) applies to the data made available in this article, unless otherwise stated in a credit line to the data. 
the prevention of HCD-induced myocardial inflammation could be a feasible approach to prevent deleterious cardiac complications.

Nowadays, lipid-lowering therapies are not only targeting lipid profiles to lower the risk of atherosclerotic cardiovascular disease (ASCVD), but also focusing on cholesterol-independent mechanisms such as cardiac endpoints [12, 13]. For instance, statin is a first-line drug for treating dyslipidaemia with additional pleiotropic effects on both antioxidation and anti-hypertrophy which are associated with the improvement of the heart structure and its functions [14]. Despite the widespread usage of this drug, long-term treatment should be investigated regarding its potential complications and non-adherence that may cause major clinical implications in certain patients [12]. Alternatively, eating functional foods that are healthy and contain hypolipidemic and antioxidant properties could be an attractive choice for helping to manage hyperlipidaemia [15].

Pineapples are a popular tropical fruit that have a high nutritional value and medicinal properties. They are consumed worldwide and are easily incorporated into daily diets. It contains an abundance of dietary fibre and phytochemicals such as gallic acid, catechin, epicatechin and ferulic acid. These biologically active compounds provide powerful natural pharmacological activities $[16$, 17]. Several studies have reported on the health benefits of pineapple consumption as highlighted by anti-obesity, anti-dyslipidaemia, antioxidant, and anti-inflammatory properties [16-19]. However, few studies have focused on the effect of pineapple consumption on cardiac oxidative stress and inflammation in hypercholesterolemia model. Here, we hypothesized that daily pineapple intake could reduce cardiac oxidative stress and inflammation in HCD-induced hypercholesterolemia rats. This study will provide information for the cardioprotective effect of pineapple consumption in relation to dyslipidaemia.

\section{Materials and methods Pineapple preparation}

Pineapple (Ananas comosus L.) cv. Pattavia which is grown in Thailand was used in this study. The pineapples were weighed, sliced, and dried at $60{ }^{\circ} \mathrm{C}$ for $96 \mathrm{~h}$ using a hot air oven. The dried pineapple slices were weighed and ground into fine powder, then stored at $-20{ }^{\circ} \mathrm{C}$ until further study.

\section{Evaluation of active compounds, antioxidant capacity and approximate analysis}

Total phenolic content was determined by using FolinCiocalteu's colorimetric method [20]. $10 \mathrm{mg}$ of dried pineapple was incubated in $1 \mathrm{~mL}$ ethanol for $48 \mathrm{~h}$ and then sonicated for $20 \mathrm{~min}$. The samples were filtered, then $20 \mu \mathrm{L}$ of the solution was transferred into a 96-well microplate and mixed with $100 \mu \mathrm{L}$ of Folin-Ciocalteu's working reagent. After $5 \mathrm{~min} 80 \mu \mathrm{L}$ of $7.5 \%$ (w/v) $\mathrm{Na}_{2} \mathrm{CO}_{3}$ was added and incubated in a dark room for $30 \mathrm{~min}$. The absorbance was measured at $765 \mathrm{~nm}$ and the total phenolic content was calculated by using the linearity of gallic acid.

Total flavonoid content was determined using the method described by Chang et al. [21]. $10 \mathrm{mg}$ of dried pineapple was incubated with $1 \mathrm{~mL}$ ethanol for $48 \mathrm{~h}$ followed by sonication for $20 \mathrm{~min}$. The samples were filtered, then $500 \mu \mathrm{L}$ of the solution was mixed with $1.5 \mathrm{~mL}$ of ethanol. After that, $100 \mu \mathrm{L}$ of $10 \%(\mathrm{w} / \mathrm{v})$ Aluminum chloride $\left(\mathrm{AlCl}_{3}\right)$ and $100 \mu \mathrm{L}$ of $1 \mathrm{M}$ Potassium acetate $\left(\mathrm{CH}_{3} \mathrm{COOK}\right)$ were added. The volume was made up to $5 \mathrm{~mL}$ using distilled water and placed in the dark at room temperature for $30 \mathrm{~min}$. Quercetin was used as a standard curve at a wavelength $415 \mathrm{~nm}$.

The 1,1-diphenyl-2-picrylhydrazyl (DPPH) assay described by Brand-Williams et al. [22] was performed to evaluate antioxidant capacity of the pineapple in this study. Dried pineapple was mixed with ethanol at the concentrations of $375,750,1,500,3,000,6,000$, and $12,000 \mu \mathrm{g} / \mathrm{mL}$, then $100 \mu \mathrm{L}$ of the samples were transferred into a 96-well microplate and mixed with $100 \mu \mathrm{L}$ of $200 \mu \mathrm{M}$ DPPH followed by incubation in the dark for $30 \mathrm{~min}$. The absorbance was measures at $517 \mathrm{~nm}$ and the antioxidant capacity was determined by using the linearity of the standard Trolox curve.

The 2,2'-azinobis-(3-ethylbenzothiazoline-6-sulfonate) (ABTS) method was described by Arnao et al. [23] to determine the pineapples antioxidant capacity. The dried pineapple was prepared with similar concentrations as above by using $50 \mu \mathrm{L}$ of the samples mixed with $100 \mu \mathrm{L}$ of working ABTS solution and then incubated for $15 \mathrm{~min}$, followed by the Trolox being used as a standard curve at a wavelength of $734 \mathrm{~nm}$.

The proximate components of the dried pineapple, which included ash, carbohydrates, fat, moisture, protein, and dietary fibre were analyzed at the Central Lab Thai, Bangkok, Thailand, according to standard protocols.

\section{Animal model}

All animal experiments were approved by the Animal Ethics Committee of Naresuan University, Thailand (approval number: NU-AE610409), and performed according to the regulations of the institutional guidelines for the care and use of laboratory animals. Four week old Four-week-old male Sprague-Dawley rats that weighed 150-200 g were obtained from Nomura Siam International Co., Ltd. Bangkok, Thailand, and housed at the Centre for Animal Research, Naresuan University in Phitsanulok, Thailand. The rats were maintained in a 
controlled temperature environment at $25 \pm 2{ }^{\circ} \mathrm{C}$, a $12 \mathrm{~h}$ light-dark cycle with a standard diet and filtered water ad libitum for 1 week. After the rats were acclimatized, they were randomly divided into 5 groups $(n=5-6)$ and treated for 8 weeks: control with standard diet and normal drinking water (control), high-cholesterol diet (standard diet $+1.5 \%(\mathrm{w} / \mathrm{w})$ of cholesterol, $0.37 \%(\mathrm{w} / \mathrm{w})$ of cholic acid) (HCD), high-cholesterol diet with a lowdose of pineapple; LPA (100 mg/kg/day) (HCD+LPA), high-cholesterol diet with a high-dose of pineapple; HPA (200 $\mathrm{mg} / \mathrm{kg} /$ day) (HCD+HPA), and high-cholesterol diet with simvastatin $(40 \mathrm{mg} / \mathrm{kg} /$ day $)(\mathrm{HCD}+\mathrm{S})$. Their body weights were determined weekly, and their total food consumptions were measured daily. The powdered pineapple and the simvastatin were administered by oral gavage.

\section{Heart and serum collection}

At the end of the 8-weeks dietary schedule, the rats were fasted overnight then anesthetized with pentobarbital sodium (Nembutal ${ }^{\circledR}$ Sodium Solution CII; $100 \mathrm{mg} /$ kg; Akorn, Inc., Lake Forest, IL, USA) and lithium heparin (150 U; Government Pharmaceutical Organization, Bangkok, Thailand) via an intraperitoneal injection. Then an operation on the rats was carried out to expose their thoracic cavities, after the incision area had been cleaned with $70 \%(\mathrm{v} / \mathrm{v})$ ethanol. Their hearts were weighed then snap-frozen in liquid nitrogen and stored at $-80{ }^{\circ} \mathrm{C}$. The blood samples were collected rapidly from the thoracic cavity and centrifuged at $3000 \times g$ for $10 \mathrm{~min}$ at $4{ }^{\circ} \mathrm{C}$. The Serum was then collected and immediately snap-frozen in liquid nitrogen and kept at $-20^{\circ} \mathrm{C}$, followed by its biochemical parameters being measured within $24 \mathrm{~h}$.

\section{Determination of blood biochemistry}

Total cholesterol (TC), high-density lipoprotein cholesterol (HDL-C), Low-density lipoprotein cholesterol (LDL-C), triglyceride (TG), aspartate amino-transferase (AST) activity, alanine amino-transferase (ALT) activity, blood urea nitrogen (BUN) as well as creatinine $(\mathrm{Cr})$ were analyzed using an automate biochemistry analyzer (cobas c 111 analyzer). Atherogenic Coefficient (AC) was calculated by (TC-HDL-C)/HDL-C and Cardiac risk ratio (CRR) was evaluated following this formula; $\mathrm{CRR}=\mathrm{TC}$ / HDL-C [24].

\section{Hearts homogenization and protein extraction}

The frozen heart tissues were thawed and homogenized in cold phosphate buffer saline (PBS) containing a protease inhibitor cocktail (CAT. 0589295301, ROCHE, Germany; $100 \mu \mathrm{L} / 100 \mathrm{mg}$ ) by using a pestle and mortar. The homogenized tissues were then centrifuged at $14,000 \times g$ for $10 \mathrm{~min}$ at $4{ }^{\circ} \mathrm{C}$ and the supernatants were collected for determining the protein concentration by using the Bradford assay (BIO-RAD, USA) as previously described [25].

\section{Protein carbonyl assay}

To determine the protein carbonyls content in oxidized protein, the 2,4-dinitrophenylhydrazine (DNPH) spectrophotometric assay was performed as previously describe [26]. Pre-analytical quality controls that included linearity test, within-run precision assay, and between day precision were determined using the control serum (HUMATROL P) with the DNPH spectrophotometric assay.

\section{Determination of inflammatory cytokine levels}

The determination of inflammatory cytokine levels that included tumor necrosis factor-alpha (TNF- $\alpha$; CAT. 900M73; Prepotech ${ }^{\circledR}$, USA), interleukin 1-beta (IL1- $\beta$; CAT. 900-M91; Prepotech ${ }^{\circledR}$, USA), and interleukin 6 (IL-6; CAT. 900-M86; Prepotech ${ }^{\circledR}$, USA), were performed using the enzyme-linked immunosorbent assay (ELISA) Buffer Kit (CAT. 900-K00; Prepotech ${ }^{\circledR}$, USA) according to the manufacturer's instructions.

\section{Lipid peroxidation assay}

Malondialdehyde (MDA) levels were measured by using the Lipid Peroxidation Assay Kit (ab118970; Abcam, Cambridge, UK). The hearts were homogenized on ice in $303 \mu \mathrm{L}$ MDA lysis buffer and centrifuged at $14,000 \times g$ for $10 \mathrm{~min}$ at $4{ }^{\circ} \mathrm{C}$. This was followed by $200 \mu \mathrm{L}$ of the supernatant being mixed with $600 \mu \mathrm{L}$ of the thiobabituric acid (TBA) solution, incubated at $95{ }^{\circ} \mathrm{C}$ for $60 \mathrm{~min}$ and then cooled on ice for a further $10 \mathrm{~min}$, after which $200 \mu \mathrm{L}$ of the mixed solution was added to a 96-well microplate. The MDA level was calculated with standard curve at a wavelength $532 \mathrm{~nm}$ and calculated following the manufacturer's protocols.

\section{Measurements of total antioxidant capacity of the heart tissue}

The Total Antioxidant Capacity Assay Kit (ab65923; Abcam, Cambridge, UK) was used to evaluate the total antioxidant capacity (TAC) of the heart tissues. Then they were washed with cold phosphate buffer saline (PBS) and subsequently homogenized. The heart homogenate was incubated on ice for $10 \mathrm{~min}$ and centrifuged at $14,000 \times g$ for $10 \mathrm{~min}$ at $4{ }^{\circ} \mathrm{C}$. The supernatant was transferred to a 96-well microplate, then a $100 \mu \mathrm{L} \mathrm{CU} 2+$ of the working solution was added. After being incubated on a shaker for $90 \mathrm{~min}$ at room temperature in the dark, the absorbance was measures at $570 \mathrm{~nm}$ and the antioxidant capacities were determined by using the linearity of the standard Trolox curve according to the manufacturer's protocols. 


\section{Statistical analysis}

All the data was expressed as the mean \pm SEM. One-way analysis of variance (ANOVA) followed by Turkey's post hoc analysis being performed using GraphPad Prism 5.0. $p$ value $<0.05$ was considered as statistically significance.

\section{Results}

Percentage yield, total phenolic content, total flavonoid content, and oxidant scavenging capacity of the pineapple After drying $4500 \mathrm{~g}$ of fresh pineapple in a hot air oven, the total yield of powder was $600 \mathrm{~g}$ which equated to $13.33 \%$ of its original weight. The total phenolic and flavonoid contents were $11.17 \mathrm{mg} \mathrm{GAE} / 100 \mathrm{~g}$ and $6.33 \mathrm{mg}$ $\mathrm{QE} / 100 \mathrm{~g}$, respectively. To determine the antioxidant capacity of the pineapple, the DDPH assay and the ABTS oxidant scavenging method were performed. The pineapple had a dose-dependent effect on percentage oxidant scavenging. The maximal tested dose of dried pineapple at $12,000 \mu \mathrm{g} / \mathrm{mL}$ was $78.38 \pm 0.91 \%$ by the DDPH method, while the ABST method was 97.93\% (Table 1). The half maximal inhibitory concentration $\left(\mathrm{IC}_{50}\right)$ values were calculated by $\log$ [concentration] (data not shown). The $\mathrm{IC}_{50}$ of the pineapple on oxidant scavenging using the DDPH and ABTS methods were $5,619 \mu \mathrm{g} / \mathrm{mL}$ and $1,265 \mu \mathrm{g} / \mathrm{mL}$, respectively. Proximate analysis showed the components of the dried pineapple had high carbohydrates at $87.72 \mathrm{~g} / 100 \mathrm{~g}$, low fat at $1.66 \mathrm{~g} / 100 \mathrm{~g}$ and high dietary fiber at $9.07 \mathrm{~g} / 100 \mathrm{~g}$ (Table 2). These results

Table 1 Percentage oxidant scavenging of the dried pineapple

\begin{tabular}{lll}
\hline $\begin{array}{l}\text { Concentration of } \\
\text { pineapple }(\mu \mathrm{g} / \mathrm{mL})\end{array}$ & $\begin{array}{l}\text { \% Oxidant scavenging } \\
\text { (DPPH assay) }\end{array}$ & $\begin{array}{l}\text { \% Oxidant } \\
\text { scavenging (ABTS } \\
\text { assay) }\end{array}$ \\
\hline 375 & $5.65 \pm 2.58$ & 21.31 \\
750 & $9.05 \pm 2.90$ & 34.35 \\
1500 & $16.73 \pm 2.35$ & 50.18 \\
3000 & $28.59 \pm 3.02$ & 64.22 \\
6000 & $47.51 \pm 3.09$ & 90.16 \\
12,000 & $78.38 \pm 0.91$ & 97.93 \\
\hline
\end{tabular}

indicated that phenolic and flavonoid compounds were present in the pineapple powder with a high antioxidant capacity.

\section{Effects of Pineapple consumption on body weight, heart weight/body weight ratio, blood parameters, atherogenic coefficient, and cardiac risk ratio}

Starting from the second week, the high cholesterol diet fed rats significantly increased their body weight when compared to the control group. Daily intake of $100 \mathrm{mg} /$ $\mathrm{kg}$ of pineapple (LPA) or $200 \mathrm{mg} / \mathrm{kg}$ of pineapple (HPA) for 8 weeks significantly decreased body weight from the third week to the end of the experiment compared with the HCD group $(p<0.05)$ (Fig. 1a), while the food intake remained unchanged in all groups. At week 8 , there were no significant differences in the heart and body weight ratios, $\mathrm{Cr}$ and $\mathrm{BUN}$ in all the groups (Figs. 1b, 3a, b). The administration of HPA dramatically reduced the TC, LDL-C, AST and ALT serum levels compared to the HCD group and similar changes were observed in the simvastatin treatment group $(p<0.05)$ (Figs. 2a, d, 3c, d). The TG serum showed a reducing trend in both the HCD+LPA and HCD+HPA groups (Fig. 2b). The HCD group showed significantly lower levels of HDL-C serum than the other groups, while there was a slight increase of HDL in both the HCD+LPA and HCD+HPA groups (Fig. 2c). The HCD-C group also had dramatically higher AC and CRR, while the HPA group showed significantly lower levels of them, which was similar to the simvastatin treated group $(p<0.05)($ Fig. 2e, f).

These results indicated that daily consumption of pineapple can control body weight and improve hyperlipidemia, AC, CRR including reduced lipid induced-hepatic toxicity in the HCD-fed rats.

\section{Pineapple consumption decreased HCD-induced oxidative stress in rat's hearts}

To examine the effect of pineapple consumption on oxidative stress and antioxidant status of the heart, the cardiac protein carbonyl (cPC) content, MDA level and total

Table 2 The biochemical compositions of the dried pineapple

\begin{tabular}{lcc}
\hline Analysis & $\begin{array}{l}\text { Amount of analytes (g/100 g dry weight of } \\
\text { pineapple) }\end{array}$ & Analysis methods \\
\hline Ash & 2.64 & AOAC (2016) 920.153 \\
Carbohydrate & 87.72 & In-house method TE-CH-169 based on Compendium of \\
& 1.66 & Methods for Food Analysis Thailand, 1st Edition, 2003 \\
Fat & 3.57 & AOAC (2016) 922.06 \\
Moisture & 4.41 & In-house method based on AOAC (2016) 934.06 \\
Protein (\%N $\times 6.25)$ & 9.07 & In-house method TE-CH-042 based on AOAC (2016) 981.10 \\
Dietary Fiber & & In-house method TE-CH-076 based on AOAC (2016) 985.29 \\
\hline
\end{tabular}



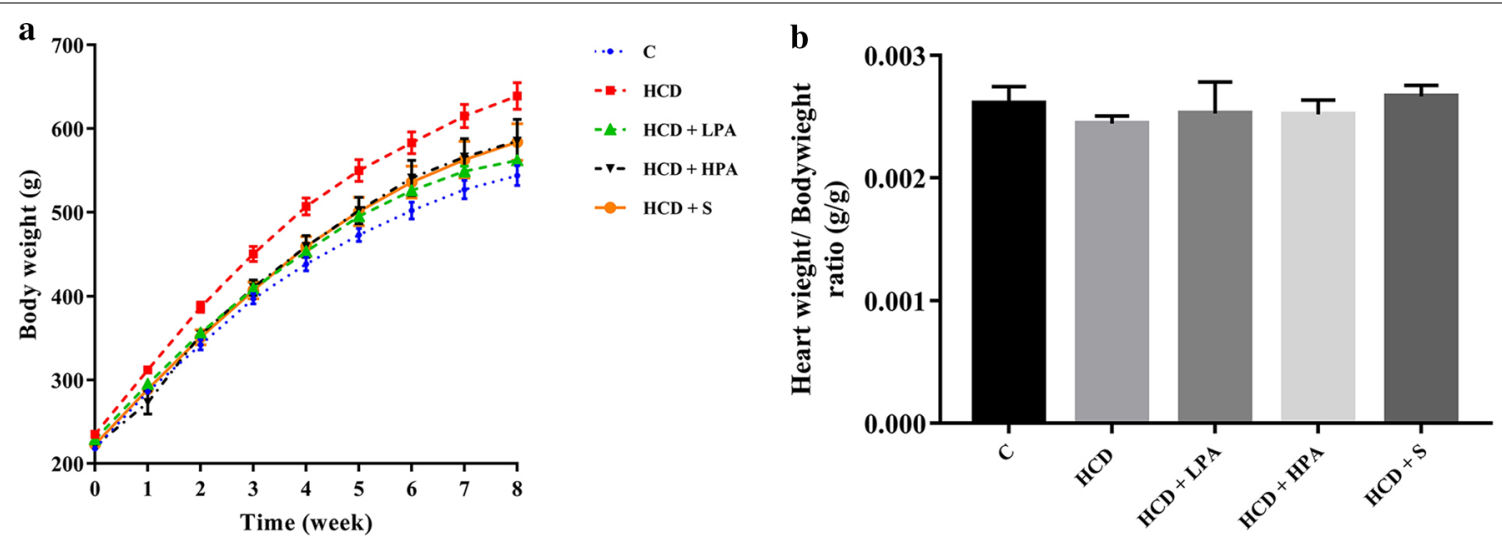

Fig. 1 The determination of eight weeks of pineapple consumption on body weight (BW; g) and heart weight (HW; g) / BW ratio (g). a Representative growth curve of male Sprague-Dawley rats; $\mathbf{b}$ HW/BW ratio of experimental groups. Data were presented as mean \pm SEM., $(n=5-6$ per group)
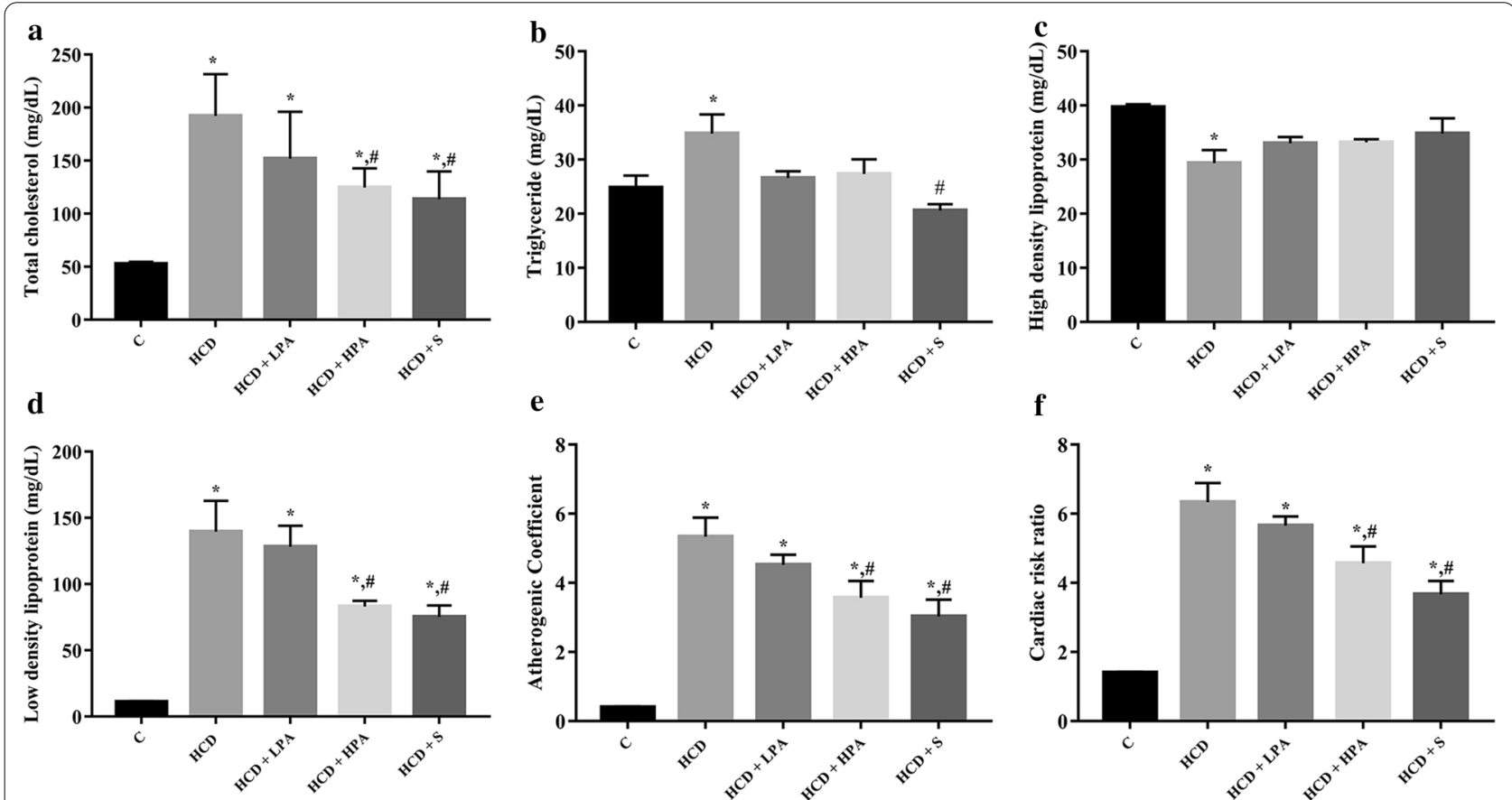

Fig. 2 The effects of eight weeks of pineapple consumption on the serum lipid profiles in high-cholesterol fed rats. After 8-weeks, blood samples in all experimental groups were collected. Atherogenic Coefficient (AC) and Cardiac risk ratio (CRR) were calculated. a Total cholesterol (TC); b Triglyceride (TG); c High-density lipoprotein cholesterol (HDL-C); $\mathbf{d}$ Low-density lipoprotein cholesterol (LDL-C); e Atherogenic Coefficient (AC); $\mathbf{f}$ Cardiac risk ratio (CRR). Each bar presented in mean \pm SEM. ${ }^{*} p<0.05$ VS the control group, $\# p<0.05$ versus the HCD group, $(n=5-6$ per group)

antioxidant capacities of the HCD model were determined. There was a significance reduction of $\mathrm{cPC}$ content in the HCD group $(0.13 \pm 0.006 \mathrm{nmol} / \mathrm{mg}$ versus $0.16 \pm 0.012 \mathrm{nmol} / \mathrm{mg}, p<0.016)$ but increased the cPC content in both the HCD+LPA and HCD+HPA groups, when compared with the HCD group $(0.15 \pm 0.004 \mathrm{nmol} /$ $\mathrm{mg}, 0.016 \pm 0.003 \mathrm{nmol} / \mathrm{mg}$ versus $0.13 \pm 0.006 \mathrm{nmol} /$ $\mathrm{mg}, p<0.018$ and $p<0.008$, respectively) (Fig. 4a). On the other hand, The MDA level in the HCD group was significantly higher than the control group $(0.34 \pm 0.024 \mathrm{nmol} /$ $\mathrm{mg}$ versus $0.23 \pm 0.0026 \mathrm{nmol} / \mathrm{mg}, \quad p<0.005)$. After 8 -weeks consumption of both the LPA and HPA, the MDA level was significantly lower than the HCD group $(0.22 \pm 0.019 \mathrm{nmol} / \mathrm{mg}, 0.019 \pm 0.024 \mathrm{nmol} / \mathrm{mg}$ versus $0.34 \pm 0.024 \mathrm{nmol} / \mathrm{mg}, p<0.004$ and $p<0.001$, respectively) (Fig. $4 \mathrm{~b}$ ). However, there were no significant 

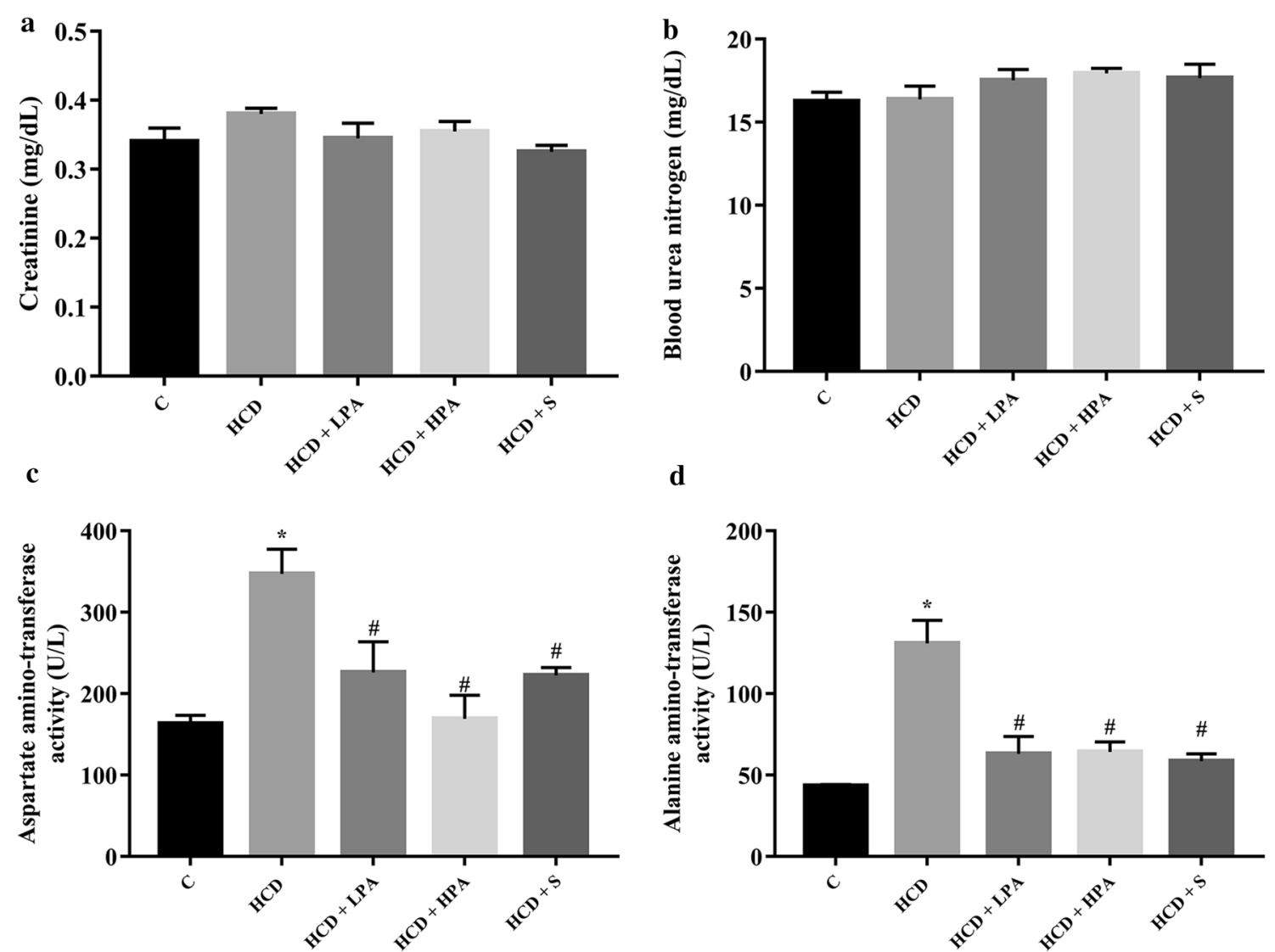

Fig. 3 The effects of eight weeks of pineapple consumption on the renal and liver functions in high-cholesterol fed rats. a Creatinine (Cr); $\mathbf{b}$ Blood urea nitrogen (BUN); c Aspartate amino-transferase (AST) activity; d Alanine amino-transferase (ALT) activity. Each bar presented in mean \pm SEM. ${ }^{*} p<0.05$ VS the control group, $\# p<0.05$ versus the HCD group, $(n=5-6$ per group)
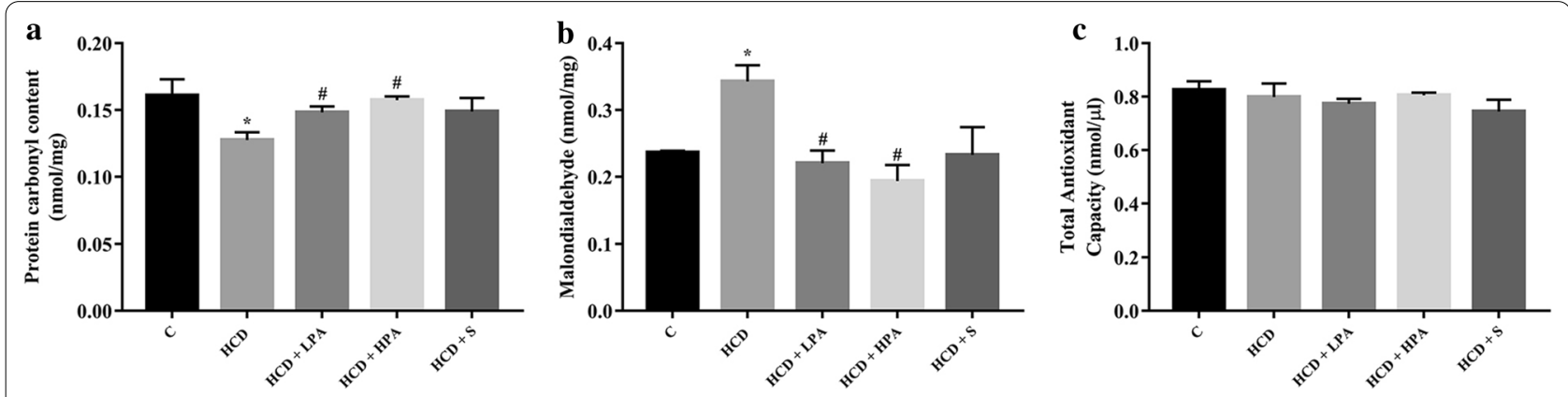

Fig. 4 The determination of eight weeks of pineapple consumption on cardiac oxidative stress. Heart tissues were homogenized followed by extraction of protein. a Cardiac protein carbonyl content (CPC); b malondialdehyde (MDA); c total antioxidant capacity (TAC). Each bar presented in mean \pm SEM. ${ }^{*} p<0.05$ VS the control group, \#p<0.05 versus the HCD group, $(n=5-6$ per group)

differences of the total antioxidant capacity in all the groups (Fig. 4c). These results revealed that daily intake of pineapple can reduce the oxidative modified lipids, but not the proteins, and does not modulate the antioxidant activities in the hearts of the HCD-fed rats.

\section{Pineapple consumption reduced cardiac inflammation} in the HCD fed rats

To explore the anti-inflammatory effect of pineapple consumption in HCD-induced cardiac inflammation, heart tissues were harvested to determine the level of the 
inflammatory cytokines. The results showed no significant difference of the cardiac TNF- $\alpha$ level in all groups (Fig. 5a). The HCD group showed a higher cardiac IL-6 level $(4760 \pm 192.5 \mathrm{ng} / \mathrm{mL}$ versus $3760 \pm 227.2 \mathrm{ng} / \mathrm{mL}$, $p<0.026$ ) (Fig. 5b), with an increasing trend of the cardiac IL-1 $\beta$ level when compared to the control group (Fig. 5c). After administering HPA for 8-weeks, the cardiac IL- 6 and IL-1 $\beta$ levels in the HCD-fed rats were significantly reduced, compared to the HCD group $(3197 \pm 278.2 \mathrm{ng} / \mathrm{mL}$ versus $4,760 \pm 192.5 \mathrm{ng} / \mathrm{mL}$, $p<0.016$ and $185 \pm 13.67 \mathrm{ng} / \mathrm{mL}$ versus $282.1 \pm 33.29 \mathrm{ng} /$ $\mathrm{mL}, p<0.013$ ) (Fig. 5b,c), while the treatment of simvastatin revealed a tendency to reduce both the cardiac IL-6 and IL-1 $\beta$ levels. These results demonstrated that the consumption of HPA ameliorated HCD-induced cardiac inflammation.

\section{Discussion}

The major findings in the present study demonstrated that pineapple contains potent radical scavenging phenolic and flavonoid compounds. In an animal model, daily intake of pineapple offers significant health benefits for body weight control, anti-dyslipidaemia and reduced hepatic injury in the HCD-induced hypercholesterolemic rats. It was also found that pineapple consumption reduced hypercholesterolemia-induced myocardia lipid peroxidation and inflammation.

A typical feature of hyperlipidaemia is an excessive lipid accumulation in the body, which is prone to promoting obesity $[5,18]$. In this study, the HCD group significantly increased BW after two weeks of treatment. Interestingly, both pineapple consumption and simvastatin treatment significantly attenuated the HCD-induced body weight gain without affecting heart to body weight ratio. In comparison to the HCD group, a daily high-dose of pineapple consumption showed a 35 and $40.5 \%$ reduction of TC and LDL-C serum, respectively, as well as approximately $46 \%$ of simvastatin. The tendency of lipid and BW reduction was similar to the simvastatin treatment and the efficacy of weight control by pineapple consumption was related to the lowering of lipid serum. The daily intake of pineapple did not affect the appetite and food consumption of the rats. Similarly, El-Shazly et al. found that pineapple juice suppressed HFD-induced obesity by decreasing lipid serum, weight gain, and hepatic lipid accumulation through decreased lipogenesis and increased lipolysis at the transcriptional level of lipid metabolism-related genes [18].

It is well-known that dietary fibre plays an essential role in promoting several physiological and metabolic beneficial effects, particularly as a bulking agent, normalising intestinal motility, preventing constipation, and decreasing the intestinal absorption of cholesterol and glucose $[27,28]$. The dried pineapple used in this study contains a high dietary fibre content of approximately $9 \%$ by weight. It was also recently reported that a highfibre diet prevented corpulence and decreased TC, TG, LDL-C levels in obesity [29]. In addition, it also provided benefits for the gastrointestinal tract included increased pre-biotic, the shifting of gut microbiota, and enhancing bacterial fermentation in relation to short-chain fatty acids (SCFAs) production [30], which is closely associated with body weight control and the prevention of hyperlipidaemia [30,31]. However, the effects of pineapple consumption and the role of gut microbiota in hypercholesterolemia requires further investigation. Moreover, evidences suggest that simvastatin reduces the risk of cardiovascular events $[32,33]$. Atherogenic indexes of atherogenic and antiatherogenic lipoproteins have emerged as predictive markers for cardiovascular diseases [24]. The atherogenic coefficient and the cardiac risk ratio are powerful indicators of cardiovascular risk; the higher the value, the higher the risk of developing coronary heart disease (CHD) [34]. Daily consumption of pineapple
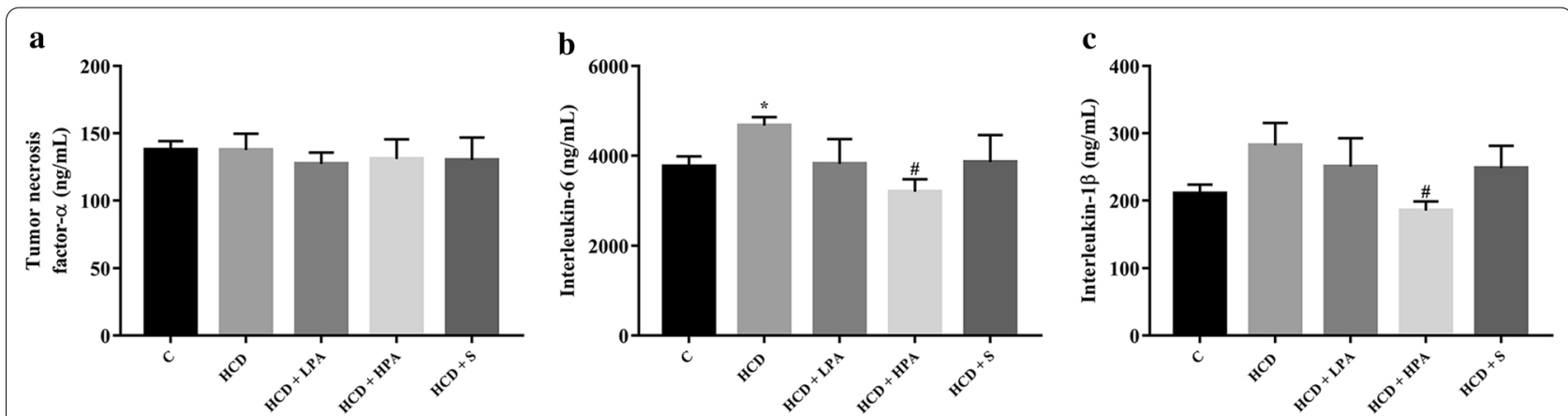

Fig. 5 The determination of eight weeks of pineapple consumption on cardiac inflammation. Inflammatory cytokines were analysed by ELISA. a Tumor necrosis factor-alpha (TNF-a); b interleukin-6 (IL-6); c interleukin-1 beta (IL-1 $\beta)$. Each bar presented in mean \pm SEM. * $p<0.05$ VS the control group, \#p<0.05 versus the HCD group, $(n=5-6$ per group) 
reduced the atherogenic coefficient and cardiac risk ratio in a similar manner to the simvastatin treatment. Therefore, pineapple is an ideal addition to a daily diet, because it can provide an additional lipid-lowering effect which could enable the reduction of medication and serve as a potential functional food for cardiovascular health.

Hypercholesterolemia is associated with elevated cardiac oxidative stress [10]. However, the effect of pineapple consumption on the heart particularly oxidative stress and the inflammation of hypercholesterolemia remains poorly understood. The heart is a highly rated metabolic organ, primarily fuelled by lipids that uptake FAs from the circulation [2, 3]. Critical changes in substrate availability causes cardiac metabolism alterations. Excess circulation of FA levels in hypercholesterolemia creates an imbalance of the lipid uptake to the heart causing lipid accumulation [2]. Therefore, fuel substrates were shifted from glucose to triglycerides and increased fatty acid oxidation (FAO) that induced the overproduction of the reactive oxygen species (ROS), which in turn damaged the biomolecules [2, 3, 35]. Similarly, studies in metabolic syndrome models of Zucker rats and the $d b$ / $d b$ mice demonstrated reduced cardiac glucose oxidation, increased FAO, lipid accumulation, and cardiac dysfunction [2]. We explored the effects of pineapple consumption on cardiac oxidative stress in hypercholesterolemia, while MDA and $\mathrm{CPC}$ contents were used as biomarkers for lipid peroxidation and protein oxidation, respectively.

Our data demonstrated that reducing protein oxidation in an HCD-induced hypercholesterolemia model when compared to a normal myocardium. Inversely, pineapple consumption increased the protein carbonylation to a similar level as that of the simvastatin treatment and the control group. However, the elevated protein oxidation level from pineapple consumption which was similar to the control group was questionable.

This could be a possibility for an adaptive response to the HCD intake. The identification of specific modified proteins and their functions particularly in cardiac consequences of pineapple consumption requires further investigation. Cardiac lipid peroxidation increased in the HCD-induced hypercholesterolemia model, while it significantly ameliorated lipid peroxidation after pineapple consumption or simvastatin treatment. Since pineapple contains antioxidant phenolic and flavonoid compounds, its intake could reduce hypercholesterolemia-mediated oxidative stress. Therefore, pineapple consumption is capable of attenuating cardiac oxidative stress on biomolecules indicating that it possesses cardiac antioxidant properties.

Hypercholesterolemia, being overweight and oxidative stress can induce systemic and vital organ inflammation particularly the heart through overexpression of the pro-inflammatory cytokines which are TNF- $\alpha$, IL-6, and IL-1 beta [35]. This study showed an elevation of cardiac inflammation by increasing IL- 6 in the HCD group. This is the first report to address the cardioprotective effect of pineapple that attenuates cardiac inflammation in HCD-induced hypercholesterolemia model. IL-6 mediated inflammation is also implicated in cardiovascular diseases [36] which is produced in response to host cell injury, while chronically elevated levels of it could lead to chronic inflammation and fibrotic disorders [36, 37]. The superior anti-inflammatory effect of pineapples can create therapeutic opportunities to reduce IL-6 induced cardiac injury. The polyphenolic compounds found in several fruits, especially pineapples, can inhibit IL-6 mediated inflammation [36, 37].

Regarding the safety of pineapple consumption, the hepatic enzymes and renal function were assessed for adverse effects [38]. Elevated serum levels of AST and ALT from HCD intake suggested that hypercholesterolemia induced hepatic injury. Daily pineapple consumption (in sub-chronic duration) or simvastatin treatment can reduce $\mathrm{HCD}$-induced hepatotoxicity, while renal function remained unaffected in all treated groups. Taking into consideration that daily pineapple consumption has no adverse effects, several studies have reported its beneficial effects for decreasing hepatic lipid accumulation, as well as hepatic injury in HFD and alcohol-induced oxidative stressed models $[18,19]$. Pineapple consumption of $100-200 \mathrm{mg} / \mathrm{kg}$ in the animal model is equivalent to $37.5-75 \mathrm{~g}$ of fresh pineapple for adults weighing $50 \mathrm{~kg}$. The cardioprotective properties of pineapple are affordable and should be incorporated into daily diets.

Overall, daily intake of pineapple provides benefits to health and could be considered as a functional food for cardiovascular condition caused by HCD. The major polyphenolics in pineapples, the molecular mechanisms of antioxidative stress and anti-inflammation in the heart tissue as well as its long-term effects requires further investigation for safe and effective implementation.

\section{Conclusions}

Pineapple possesses antioxidant and lipid-lowering properties, therefore, daily consumption can reduce hypercholesterolemia-induced cardiac lipid peroxidation and pro-inflammation in an in vivo model. This study has demonstrated that pineapple is a potential candidate for cardioprotection against hypercholesterolemia.

\section{Abbreviations}

HCD: High-cholesterol diet; AC: Atherogenic coefficient; CRR: Cardiac risk ratio; CPC: Cardiac protein carbonyl; MDA: Malondialdehyde; ASCVD: Atherosclerotic cardiovascular disease; LPA: Low-dose pineapple; HPA: High-dose pineapple; S: Simvastatin; TC: Total cholesterol; HDL-C: High-density lipoprotein cholesterol; LDL-C: Low-density lipoprotein cholesterol; TG: Triglyceride; AST: Aspartate 
amino-transferase; ALT: Alanine amino-transferase; BUN: Blood urea nitrogen; Cr: Creatinine; TNF-a: Tumor necrosis factor-alpha; IL 1- 3 : Interleukin 1-beta; IL6: Interleukin 6; TAC: Total antioxidant capacity; SCFAs: Short-chain fatty acids; CHD: Coronary heart disease; FAO: Fatty acid oxidation.

\section{Acknowledgements}

We would like to thank Prof. Dr. Nuntavan Bunyapraphatsara and Assoc. Prof. Dr. Suwan S. Thirawarapan for their support. We are grateful to the Center for Animal Research, Naresuan University for their excellent technical assistance. We would like to thank Mr. Peter Barton from the Division of International Affairs and Language Development (DIALD), Naresuan University, for proof reading and editing the English of this work.

\section{Authors' contributions}

PS, WM, SK, and NN conceived and designed the experiments; PS, WM, RC, SK, and NN performed the experiments; PS, SK, and NN analyzed the data; PS, WM, SK and NN contributed reagents/materials/analysis tools; PS, SK, and NN wrote and prepared and edited the manuscript. All authors read and approved the final manuscript.

\section{Funding}

This study was financially supported by The Thailand Research Fund (TRF) No. RDG6120043.

\section{Availability of data and materials}

The datasets during and/or analysed during the current study available from the corresponding author on reasonable request.

\section{Declarations}

\section{Ethics approval and consent to participate}

All animal experiments were performed according to the regulation of institutional guidelines for the care and use of laboratory animals and were approved by the Animal Ethics Committee of Naresuan University, Thailand (approval number: NU-AE610409).

\section{Consent for publication}

Not applicable.

\section{Competing interests}

The authors declare no competing interests.

\section{Author details}

${ }^{1}$ Integrative Biomedical Research Unit (IBRU), Faculty of Allied Health Sciences, Naresuan University, Phitsanulok 65000, Thailand. ${ }^{2}$ Department of Cardio-Thoracic Technology, Faculty of Allied Health Sciences, Naresuan University, Phitsanulok 65000, Thailand. ${ }^{3}$ Biomedical Engineering Institute (BMEl), Chiang Mai University, Chiang Mai 50200, Thailand. ${ }^{4}$ Department of Physiology, Faculty of Medical Sciences, Naresuan University, Phitsanulok 65000, Thailand. ${ }^{5}$ Department of Chemistry, Faculty of Sciences, Naresuan University, Phitsanulok 65000, Thailand.

Received: 8 July 2020 Accepted: 31 March 2021

Published online: 07 April 2021

\section{References}

1. Yao YS, LiTD, Zeng ZH. Mechanisms underlying direct actions of hyperlipidemia on myocardium: an updated review. Lipids Health Dis. 2020;19:23.

2. Scherer PE, Hill JA. Obesity, diabetes, and cardiovascular diseases: a compendium. Circ Res. 2016;118:1703-5.

3. Pascual F, Coleman RA. Fuel availability and fate in cardiac metabolism: a tale of two substrates. Biochim Biophys Acta. 2016;1861:1425-33.

4. Cortassa S, Sollott SJ, Aon MA. Mitochondrial respiration and ROS emission during $\beta$-oxidation in the heart: An experimental-computational study. PLoS Comput Biol. 2017;13:e1005588.

5. Han Q, Yeung SC, Ip MSM, Mak JCW. Dysregulation of cardiac lipid parameters in high-fat high-cholesterol diet-induced rat model. Lipids Health Dis. 2018;17:255.
6. Ruiz-Ramírez A, López-Acosta O, Barrios-Maya MA, El-Hafidi M. Cell death and heart failure in obesity: role of uncoupling proteins. Oxid Med Cell Longev. 2016;2016:9340654.

7. Christoffersen C, Bollano E, Lindegaard ML, Bartels ED, Goetze JP, Andersen CB, et al. Cardiac lipid accumulation associated with diastolic dysfunction in obese mice. Endocrinology. 2003;144:3483-90.

8. Goldberg IJ, Reue K, Abumrad NA, Bickel PE, Cohen S, Fisher EA, et al. Deciphering the role of lipid droplets in cardiovascular disease: a report from the 2017 national heart, lung, and blood institute workshop. Circulation. 2018;138:305-15.

9. Hu Q, Zhang H, Gutiérrez Cortés N, Wu D, Wang P, Zhang J, et al. Increased Drp1 acetylation by lipid overload induces cardiomyocyte death and heart dysfunction. Circ Res. 2020;126:456-70.

10. Hauck AK, Bernlohr DA. Oxidative stress and lipotoxicity. J Lipid Res. 2016;57:1976-86.

11. Aon MA, Bhatt N, Cortassa SC. Mitochondrial and cellular mechanisms for managing lipid excess. Front Physiol. 2014;5:282-382.

12. Ward Natalie C, Watts Gerald F, Eckel RH. Statin toxicity. Circ Res. 2019;124:328-50.

13. Larsen LE, Stoekenbroek RM, Kastelein JJP, Holleboom AG. Moving Targets: recent advances in lipid-lowering therapies. Arterioscler Thromb Vasc Biol. 2019;39:349-59.

14. Liao JK. Statin therapy for cardiac hypertrophy and heart failure. J Invest Med. 2004;52:248-53.

15. Hunter PM, Hegele RA. Functional foods and dietary supplements for the management of dyslipidaemia. Nat Rev Endocrinol. 2017:13:278-88.

16. Dembitsky VM, Poovarodom S, Leontowicz $\mathrm{H}$, et al. The multiple nutrition properties of some exotic fruits: Biological activity and active metabolites. Food Res Int. 2011;44:1671-701.

17. Bataglion GA, da Silva Felipe MA, Eberlin MN, Koolen HH. Determination of the phenolic composition from Brazilian tropical fruits by UHPLC-MS/MS. Food Chem. 2015;180:280-7.

18. El-Shazly SA, Ahmed MM, Al-Harbi MS, Alkafafy ME, El-Sawy HB, Amer SAM. Physiological and molecular study on the anti-obesity effects of pineapple (Ananas comosus) juice in male Wistar rat. Food Sci Biotechnol. 2018;27:1429-38.

19. Okafor OY, Erukainure Ol, Ajiboye JA, Adejobi RO, Owolabi FO, Kosoko SB. Modulatory effect of pineapple peel extract on lipid peroxidation, catalase activity and hepatic biomarker levels in blood plasma of alcohol-induced oxidative stressed rats. Asian Pac J Trop Biomed. 2011;1:12-14.

20. Folin O, Ciocalteu V. On tyrosine and tryptophane determinations in proteins. J Biol Chem. 1927;73:627-50.

21. Chang CC, Yang MH, Wen HM, Chern JC. Estimation of Total Flavonoid Content in Propolis by Two Complementary Colorimetric Methods. J Food Drug Anal. 2002;10:178-82.

22. Brand-Williams W, Cuvelier ME, Berset C. Use of a free radical method to evaluate antioxidant activity. LWT Food Sci Technol. 1995;28:25-30.

23. Arnao M, Cano A, Acosta M. The hydrophilic and lipophilic contribution to total antioxidant activity. Food Chem. 2001;73:239-44.

24. Bo MS, Cheah WL, Lwin S, Moe Nwe T, Win TT, Aung M. Understanding the relationship between atherogenic index of plasma and cardiovascular disease risk factors among staff of an University in Malaysia. J Nutr Metabolism. 2018;2018:7027624.

25. Mongkolpathumrat P, Nokkaew N, Adulyaritthikul P, Kongpol K, Sanit J, Pankhong $\mathrm{P}$, et al. Diabetes induced internal organs inflammation in nonobese type 2 diabetic rats. J Appl Pharma Sci. 2019;9:41-9.

26. Maneewong K, Mekrungruangwong T, Luangaram S, Thongsri T, Kumphune S. Combinatorial determination of ischemia modified albumin and protein carbonyl in the diagnosis of nonst-elevation myocardial infarction. Indian J Clin Biochem. 2011;26:389-95.

27. Hu H, Zhao Q. Optimization extraction and functional properties of soluble dietary fiber from pineapple pomace obtained by shear homogenization-assisted extraction. RSC Adv. 2018;8:41117-30.

28. Selani MM, Brazaca SGC, dos Santos Dias CT, Ratnayake WS, Flores RA, Bianchini A. Characterisation and potential application of pineapple pomace in an extruded product for fibre enhancement. Food Chem. 2014;163:23-30.

29. Soliman GA. Dietary fiber, atherosclerosis, and cardiovascular disease. Nutrients. 2019;11(5):1155. 
30. Hernández MAG, Canfora EE, Jocken JWE, Blaak EE. The short-chain fatty acid acetate in body weight control and insulin sensitivity. Nutrients. 2019;11(8):1943.

31. Shimizu H, Masujima Y, Ushiroda C, Mizushima R, Taira S, Ohue-Kitano R, et al. Dietary short-chain fatty acid intake improves the hepatic metabolic condition via FFAR3. Sci Rep. 2019;9:16574.

32. Sirimarco G, Labreuche J, Bruckert E, Goldstein Larry B, Fox Kim M, Rothwell Peter $\mathrm{M}$, et al. Atherogenic dyslipidemia and residual cardiovascular risk in statin-treated patients. Stroke. 2014:45:1429-36.

33. Gamboa CM, Safford MM, Levitan EB, Mann DM, Yun H, Glasser SP, et al. Statin underuse and low prevalence of LDL-C control among U.S. adults at high risk of coronary heart disease. Am J Med Sci. 2014;348:108-14.

34. Cheraghi M, Shahsavari G, Maleki A, Ahmadvand H. Paraoxonase 1 activity, lipid profile, and atherogenic indexes status in coronary heart disease. Rep Biochem Mol Biol. 2017;6:1-7.
35. Csonka C, Sárközy M, Pipicz M, Dux L, Csont T. Modulation of hypercholesterolemia-induced oxidative/nitrative stress in the heart. Oxid Med Cell Longev. 2016;2016:3863726.

36. Omoigui S. The Interleukin-6 inflammation pathway from cholesterol to aging-role of statins, bisphosphonates and plant polyphenols in aging and age-related diseases. Immunity Ageing: I\&A. 2007;4:1-1.

37. Fontes JA, Rose NR, Čiháková D. The varying faces of IL-6: From cardiac protection to cardiac failure. Cytokine. 2015;74:62-8.

38. Meunier L, Larrey D. Drug-induced liver injury: biomarkers, requirements, candidates, and validation. Front Pharmacol. 2019;10:1482-582.

\section{Publisher's Note}

Springer Nature remains neutral with regard to jurisdictional claims in published maps and institutional affiliations.
Ready to submit your research? Choose BMC and benefit from:

- fast, convenient online submission

- thorough peer review by experienced researchers in your field

- rapid publication on acceptance

- support for research data, including large and complex data types

- gold Open Access which fosters wider collaboration and increased citations

- maximum visibility for your research: over $100 \mathrm{M}$ website views per year

At BMC, research is always in progress.

Learn more biomedcentral.com/submissions 